\title{
Present and Future Innovations in Solid Waste Management in Malaysia
}

\author{
Zaipul Anwar Zainu, Wan Md Syukri Wan Mohamad Ali and Ahmad Rahman Songip \\ Malaysia-Japan International Institute of Technology (MJIIT), Universiti Teknologi Malaysia Kuala Lumpur, \\ Jalan Semarak, 54100 Kuala Lumpur, Malaysia.
}

\begin{abstract}
Managing Solid Waste in Malaysia has become a challenging task especially in recent years due to rapid development, industrialisation, increase of population, and complexity in the types of waste being generated on daily basis. Adding to this problem, the number of landfill sites that are coming towards the end of its lifecycle are fast growing. Rapid development and industrialisation have also caused the price of land to increase significantly therefore the effort to develop new modern landfill sites become significantly expensive. On top of that, emerging type of waste such as e-waste is becoming new threats to the environment in Malaysia. Therefore new innovations in the approach towards managing solid waste are greatly needed. This paper is written to provide an analysis of how to address the issues by incorporating the present and future innovations related to solid waste management in Malaysia.
\end{abstract}

Keywords: waste management, environmental management, technology, management, innovation, Malaysia.

\section{Introduction}

One of the biggest challenges in urban areas within the country is to manage its solid waste especially in the areas where industries and housing estates are developing rapidly as economies grow. Environmental reports produced yearly by the Department of Environment (DoE) showed that lack of an effective and efficient solid waste management system has had a negative impact on the environment in the country. Malaysia, with a population of over 29 million in 2012 generates approximately 25,000 metric tonnes of domestic waste per day [1].

The average per capita generation of solid waste in Malaysia is estimated at about $0.85 \mathrm{~kg} / \mathrm{person} / \mathrm{day}$ depending on the economic and geographical status of an area. In major cities such as Kuala Lumpur it is estimated that the generation of waste is about $1.5 \mathrm{~kg} /$ person/day [2]. Currently, the waste management approach being employed is the landfill approach but due to rapid development and the lack of space for new landfills, authorities in most major cities in Malaysia are looking at other innovations in waste management approaches. One such approach is waste recycling as indicated by the Malaysian government's adoption of this method as a long-term strategy for solid waste management as stated in the 8th Malaysia Plan (2001-2005) [11].

Starting from 8th Malaysian Plan (2001-2005), the government has included "waste minimisation", "promotion of reuse", "developing a recycling-oriented", and "implementation of pilot projects for recycling" as some of its main policy goals. In the 9th Malaysian Plan (2006 - 2010) further emphasised were given to the continuation of reduce, reuse, recovery and recycling of waste as well as greater use of environmentally friendly products. As a result of this plan, a new department, known as National Solid Waste Management Department has been set up under the Ministry of Housing and Local Government [12]. A new bill has been gazetted to implement the new Solid Waste and Public Cleansing Management Corporation Act 2007 (SWPCMC Act 2007). All matters relating to solid waste management will be under the jurisdiction of this new Act. The focus area for this Act and the new department will be on Municipal Solid Waste Management [13].

The SWPCMC Act 2007 also provides executive power to the Federal Government to implement solid waste management and public cleansing activities throughout Peninsula Malaysia, Federal Territories of Putrajaya and Labuan.

Through the SWPCMC Act 2007 the Federal Government of Malaysia will be taking over the responsibility of solid waste management (SWM) from state local authorities (LA) and privatised them to concession companies. The basis for this new innovation in the management of SWM by the Federal Government is to take 
over of the responsibility from LA due to several factors such as lack of human and financial resources to manage waste and non-standardised approach to SWM among the LA themselves. Therefore the aim of the privatisation exercise is to improve the quality of service, promote efficiency, provide better facilities and to have an integrated and holistic approach to Malaysian SWM [3].

On top of that the new Act also took into consideration waste minimisation, reuse of the waste, material recycling, energy recovery and landfill.

\section{Current practise of SWM in Malaysia}

In general, based on the new Act, SWM in Malaysia involves the participation of various Government agencies from federal to state and down to LA. LA's role will be limited to receiving delegation of power from Federal Government. Nevertheless LA will be directly engaged with municipal SWM. The decision to determine whether Municipal Solid Waste (MSW) collection is implemented either by LA or private contractor is the LA's responsibility. Similarly, decision to determine the area for MSW collection will be based on the number of population by the LA.

\subsection{Logistic and collection of solid waste}

Table 1 shows the composition of waste generated per day in Peninsular Malaysia [2]. Mechanism of separation at source between recyclables and non-recyclables are done on voluntary basis by Malaysians themselves with collection mechanism by the concessionaires had started from September 2012 [2]. Since that period a two plus one $(2+1)$ collection system: 2 days for residual and 1 day for recyclable waste including bulky and green waste has been implemented. New standards on waste bin and garbage collection trucks have been used and enforcement on the efficiency of the collection schedule also has been implemented [1].

TABLE I: Waste composition generated per day in Peninsular Malaysia

\begin{tabular}{|l|c|}
\hline Type of Waste & Percentage \\
\hline Organic (Food) & $45 \%$ \\
\hline Plastics & $24 \%$ \\
\hline Paper & $7 \%$ \\
\hline Metal & $6 \%$ \\
\hline Glass \& Others & $18 \%$ \\
\hline Total & $100 \%$ \\
\hline
\end{tabular}

\subsection{Segregation, treatment, recycle and disposal}

The wastes generated are segregated, treated whenever needed and then recycled or disposed off at 165 disposal sites all over the country which cater up to $95 \%$ of Malaysian waste as a whole. Of these, only eight are sanitary landfills while the rest are open dumps. Another 11 more sanitary landfills are under various stages of implementation and construction. However, about $80 \%$ of these open dumps have almost reached full capacity and are expected to be shut down over the next few years [1]. It is a great environmental challenge to close the landfill and it will involve acquisition of other piece of land that will become scarce in the future. At the moment the country has only one Waste-to-Energy (WTE) plant located at the central region and four mini incinerators under various stages of implementation in Langkawi, Tioman and Pangkor Island plus one in Cameron Highlands.

\section{Current challenges in SWM}

The main challenges brought by the rapid increase in the amount of solid wastes are its detrimental effect to both humans and the environment. Currently, major waste management approach in Malaysia is still by landfilling and incineration method [1].

\subsection{Landfill}

Due to increasing lack of space for new landfills, authorities in major cities in Malaysia are studying other waste management approaches. Among them is an approach to move away from unsanitary landfills due to its 
capability to produce greenhouse gas (GHG) emissions such as methane and carbon dioxide. According to statistics produced by World Bank, in 2010 Malaysia produce 42.2\% more Methane, 250.5\% more carbon dioxide, 10.4\% more Nitrous Oxide and 99.9\% other type of GHG than previous years from $1990-2010$ as shown in Table 2 [4]. This is an alarming statistics and detrimental to the environment in Malaysia. New innovative and sustainable SWM technologies are urgently required to address these issues.

TABLE II: Trends in greenhouse gas emissions (GHG) [4]
\begin{tabular}{|l|c|c|}
\hline \multicolumn{1}{|c|}{$\begin{array}{c}\text { Type of gas } \\
\text { emissions }\end{array}$} & $\begin{array}{c}\text { Thousand } \\
\text { metric tons or } \\
\mathrm{CO}_{2} \text { equivalent }\end{array}$ & $\begin{array}{c}\text { \% Change } \\
1990-2010\end{array}$ \\
\cline { 2 - 3 } & 2010 & $1990-2010$ \\
\hline Carbon Dioxide & $198,348.0$ & 250.5 \\
\hline Methane & 33,599 & 42.2 \\
\hline Nitrous Oxide & 15,010 & 10.4 \\
\hline Other GHG & 1,195 & 99.9 \\
\hline
\end{tabular}

\subsection{Incineration}

Incineration is the second mostly used method to manage waste in Malaysia. It is one of the most effective means of dealing with various types of wastes. Despite being an attractive technological option for waste treatment, this combustion-based process for municipal solid waste (MSW) treatment has been intensely debated in the country [5], resulting in some of the incinerators project to be stalled. In the absence of effective controls in the operations of incinerators, harmful pollutants such as dioxins may be emitted into the air, land and water that may influence human health and environment. Although incineration of municipal waste coupled with material and energy recovery can form an essential part of an integrated waste management system, yet strict controls are required to prevent its negative impacts on human health and environment [6].

\subsection{Increasing cost of waste management}

According to Malaysia's current Director General of National Solid Waste Management Department, 40\% $80 \%$ of LA expenditure is on managing solid waste and public cleansing. The cost of SWM services per premise is around RM15.00 and the privatisation of the SWM had cost the Malaysian Government more than RM300 million per project. Capital expenditure (Capex) for a new landfill will be more than RM30 million in average whereas the operating expenditure (Opex) of a landfill is around RM30.00 - RM40.00/tonne in average [1].

In this situation, LA is in most cases incapable of responding to this high cost expenditure since the necessary resources to implement adequate solid waste management systems are generally underestimated. The absence of these consequently leads to inadequate waste management with far-reaching ramifications to both public health and the environment [7].

\subsection{Public awareness and enforcement}

The government has launched several recycling campaigns since the early years of 2000 to involve the participation of NGOs and community groups as well as the launch of an extensive public education and publicity campaign. Unfortunately the campaign received a lukewarm response from the public [8].

The overall failure of the campaign has been succinctly noted by the Minister of Housing and Local Government, in which he mentioned that after more than two years of recycling campaigns, only $2 \%$ of waste is recycled while it will takes only nine and a half days to fill the Petronas Twin Towers with garbage [8].

In fact, the figures quoted above are way below the government's target of increasing the nation's recycling rate to $22 \%$ by 2020 , which would require a drastic transformation in habits and attitudes to the Malaysian public [8].

Innovation in environmental education and awareness campaigns are among the key activities that can 
significantly reduce the amount of waste being generated. The amount of waste will continue to increase without a conscious decision by consumers to reduce, reuse and recycle. Early age education is also the key to ensure future generations contribute to sustainable SWM practices. Enforcement of regulation is another aspect to ensure rules are adhered to. Involvement of the public through aggressive campaign using social media is another aspect that could be looked into in the future [18].

\section{Future sustainable innovations in SWM}

Managing solid waste in Malaysia is a challenge that must be planned and handled properly for future generations. Innovative and sustainable methods to control the production of solid waste are the paramount important in solving this issue. Control over the production of solid waste can help reduce solid waste being sent to landfills. The production of solid waste can also be addressed by various means, such as enforcement of waste legislation, recycling; waste control at source, the design of an intelligent system for controlling the composition of solid waste, and a continuous awareness campaign on waste-related issues, among others [7].

Below are the planning and strategies that can be adopted in order to create an innovative and sustainable waste management system in Malaysia.

\subsection{Emerging hazardous waste}

The fastest growing hazardous solid waste in Malaysia currently is the e-waste (electrical and electronic waste). Since the 1980s, a massive volume of electric and electronic (E\&E) equipment has been produced, used and consumed in the country at a very high rate. This rate is increasing over time, whereas most of these products' life cycles are known to have decreased significantly [14]. Subsequently, the ever-increasing amount of waste electric and electronic equipment (e-waste) has become a common concern in many countries around the world [15], both in terms of the conservation of the environment and the reuse or recycling of such waste.

This e-waste has become a serious threat to the living environment, with increasing numbers of appliances being thrown into landfill after usage. The presence of e-waste in landfill will bring detrimental environmental impacts. This is because the hazardous components in e-waste may leach into water sources, causing contamination of water and soil thus caused increased health risks. Even a small amount of e-waste entering landfill sites potentially contain relatively high amount of heavy metals and poisonous substances [16] due to the high concentration of poisonous materials.

In 2013 the production and generation of e-waste in Malaysia is about 800,00 tonnes annually and forecasted to be 1.11 million tonnes in 2020 [17]. Currently e-waste is regarded as the most challenging waste stream in the country. In 2010, the E\&E industry was the leading sub-sector in Malaysia's manufacturing sector, contributing significantly to the country's manufacturing output. Consequently, the generation of e-waste without proper management will pose a major threat to the environment and possibly to the country's sustainable economic growth in the future.

In developed countries such as Japan and European countries, strict legislation and initiatives have been undertaken for the proper management of e-waste. In Malaysia, managing e-waste is still in its early stages. At present, e-waste management is principally market driven, though some voluntary activities are seen on a small scale. As such, now appears to be the appropriate time to innovate new approaches and systems to reduce, reuse and recycling of e-waste in Malaysia. The goal is to collect as many as possible the end-of-life products so as to increase their life cycle, or to properly dispose them to minimize their impact on the environment.

In August 2005 the Malaysian government has introduced the first e-waste law in Malaysia - the Environmental Quality (Scheduled Wastes) Regulations 2005. However the law focuses only on industrial, institutions and business entities generated e-waste. Until today there are no regulations or institutionalised system to manage household generated e-waste.

At present there are also no dedicated facilities to properly dispose the e-waste. The issue of lack of formal system of management and disposal facilities, coupled with the low level of awareness among the society have resulted in improper disposal of e-waste, where small-sized e-waste (such as mobile phones and batteries) are disposed of together with normal household waste and ended up in landfill, and bulky items (such as refrigerators, computers, television sets etc.) are being dumped indiscriminately. 
Although the amount of e-waste disposed of by each member of the society may be small, it has tremendous cumulative and collective effects. The flow of e-waste in this manner exposes the society to environmental and health hazard.

The increasing amount of e-waste being generated in Malaysia, coupled with the high possibilities of ewaste being imported from other countries demand for an innovative and holistic e-waste management framework to be put in place especially as there are evidence of indiscriminate dumping and improper disposal of e-waste.

\subsection{Reduce, Reuse and Recycling (3R) programme}

Lack of regulations and guidelines are one of the most serious problems that hinder the success of $3 \mathrm{R}$ programme, reduce, reuse and recycling programme in Malaysia. National, state and local authorities should formulate regulations, policies and programmes that would be sustainable. As an example, the programmes in Japan are carried out both through private and public systems, recycling is carried out through retailers' trade-in, barter system activities and community-based systems. While Germany has in place regulations on deposit system, waste disposal tax and amount of waste to be utilised in production [9]. Solid waste recycling in Malaysia has a long way to go. Effort to reduce waste through waste minimisation or recycling should be planned properly and to incorporate latest waste treatment technologies. The recycling programme should be properly planned involving all the stakeholders such as the government, municipalities, households, nongovernmental organisations, manufacturers and last but not least the scavengers [9]. Current recycling rate of less than 5\% maybe underestimated since recycling activities are still not regulated thus no proper data has been collected [1].

\subsection{Enhancement of infrastructure and human resource management}

In general, meaningful progress has been made in Malaysia in terms of developing SWM infrastructures, but the desired goal of a clean and green nation is yet to be attained as enough awareness on waste management issues for the public to make informed decisions with regards to SWM is yet to be realised.

Despite the fact that local governments spent almost 40\%-80\% of their operational budgets on solid waste management-related issues, the need to develop human capital that will deal with waste cannot in any way be under-estimated. These are necessary to acquire expertise to carry out the task of waste management in the various municipalities effectively and efficiently.

\subsection{Implementation of Decision Support System (DSS)}

In Malaysia, solid waste analysis and data for major towns and cities basically have not been well documented [7]. Several studies have been undertaken in the past on waste composition, but they were not undertaken using proper sampling techniques and no coordination has been done. This is a factor that could defy a good strategy to manage solid waste in this country. In other words, at the moment the there is no DSS that has been developed for current waste management system. This could hinder proper information being utilised for innovation and future planning in waste management [1].

Successful waste management in any given country depends on reliable information about quantities, types, and the amount of material that can be captured and expected to envisage proper decision making in the future. [7].

\subsection{Alternative waste treatment technologies}

In considering alternative technology to be used for managing waste, Malaysia has to take into consideration the risk, sustainability, impact on environment and commercially proven technology and reliability for long term solution.Emerging technology such as using thermal plasma waste treatment method that employs pyrolysis and/or gasification are available and looks promising but viability of the method needs to be verified. At the moment Universiti Teknologi Malaysia through its Malaysia-Japan International Institute of Technology is doing research on the viability of implementing this technology in the country.

The development of pyrolysis and gasification technologies has been successfully deployed in large-scale plants in Europe, North America and Japan [10]. Similar setup can be developed in this country especially in the area where hazardous waste has been generated and difficult to be treated such as in the petro-chemical industrial area. A political and social issue can also be avoided if such setup can be realised because this type of 
facilities has proven that it is capable of treating hazardous waste efficient and effectively in the abovementioned countries.

\section{Conclusion}

The management of solid waste in Malaysia is a challenge that must be planned and implemented efficiently. Creative and innovative ideas and strategies need to be incorporated in the planning. This should also include the inclusion of latest technologies in waste treatment strategies. Strategies to control the generation of solid waste and treatment must be among the best and most appropriate methods so as to avoid future complications. Besides that control over the production of solid waste should be able help reduce solid waste being sent to landfills. The production of solid waste can also be addressed by various means, such as enforcement of waste legislation, recycling; waste control at source, the design of an intelligent system for controlling the composition of solid waste, and a continuous awareness campaign on waste-related issues, among others [7].

However, a fundamental requirement for more efforts to increase effectiveness and efficiency in achieving the set objectives on solid waste management with an integrated and sustainable perspective is absolutely a necessity by the local, state, and federal governments for a clean, green, and environmental friendly Malaysian to cherish in the future.

\section{References}

[1] Yahaya, N. "The Way Forward: Solid Waste Managment in Malaysia." $10^{\text {th }}$ Annual Waste Management Conference \& Exhibition, Malaysia, p.10, 19 July, 2013.

[2] Budhiarta, I., Siwar, C., \& Basri, H. (2011). Current status of municipal solid waste generation in Malaysia. International Journal on Advanced Science, Engineering and Information Technology, 2(2), 16-21.

[3] Yahaya, N., \& Larsen, I. (2008). Federalising solid waste management in peninsular Malaysia. In Proceeding of International Solid Waste Association (ISWA) World Congress, Singapore.

[4] World Development Indicators, The World Bank. [Online]. Available: http://wdi.worldbank.org/table/3.9. [Accessed: 04-Aug-2013].

[5] Achillas, C., Vlachokostas, C., Moussiopoulos, N., Banias, G., Kafetzopoulos, G., \& Karagiannidis, A. (2011). Social acceptance for the development of a waste-to-energy plant in an urban area. Resources, Conservation and Recycling, 55(9), 857-863.

http://dx.doi.org/10.1016/j.resconrec.2011.04.012

[6] Misra, V., \& Pandey, S. D. (2005). Hazardous waste, impact on health and environment for development of better waste management strategies in future in India. Environment international, 31(3), 417-431.

http://dx.doi.org/10.1016/j.envint.2004.08.005

[7] Badgie, D., Samah, M. A., Manaf, L. A., \& Muda, A. B. (2012). Assessment of municipal solid waste composition in Malaysia: Management, practice and challenges. Polish Journal of Environmental Studies, 21(3), 539-547.

[8] Omran, A., Mahmood, A., Abdul Aziz, H., \& Robinson, G. M. (2009). Investigating Households Attitude Toward Recycling of Solid Waste in Malaysia: A Case Study. Int. J. Environ. Res, 3(2), 275-288.

[9] Hassan, N., Chong, T. L., Rahman, M., \& Awang, M. (2001). Recycling model in developing countries: an illustration for Malaysia. In Environmentally Conscious Design and Inverse Manufacturing, 2001. Proceedings EcoDesign 2001: Second International Symposium on (pp. 494-498). IEEE.

http://dx.doi.org/10.1109/ecodim.2001.992406

[10] Gomez, E., Rani, D. A., Cheeseman, C. R., Deegan, D., Wise, M., \& Boccaccini, A. R. (2009). Thermal plasma technology for the treatment of wastes: a critical review. Journal of Hazardous Materials, 161(2), 614-626. http://dx.doi.org/10.1016/j.jhazmat.2008.04.017

[11] Economic Planning Unit. "Eighth Malaysia Plan 2001-2005." Economic Planning Unit Malaysia (2001).

[12] Economic Planning Unit. "The 9th Malaysia plan: 2006-2010." Putra Jaya, Malaysia: Prime Minister's Department (2006).

[13] Manaf, L. A., Samah, M. A. A., \& Zukki, N. I. M. (2009). Municipal solid waste management in Malaysia: Practices and challenges. Waste management, 29(11), 2902-2906.

http://dx.doi.org/10.1016/j.wasman.2008.07.015 
[14] Mallawarachchi, H., \& Karunasena, G. (2012). Electronic and electrical waste management in Sri Lanka: Suggestions for national policy enhancements. Resources, Conservation and Recycling, 68, 44-53.

http://dx.doi.org/10.1016/j.resconrec.2012.08.003

[15] Nnorom, I. C., \& Osibanjo, O. (2008). Overview of electronic waste (e-waste) management practices and legislations, and their poor applications in the developing countries. Resources, conservation and recycling, 52(6), 843-858.

http://dx.doi.org/10.1016/j.resconrec.2008.01.004

[16] Janz, A., \& Bilitewski, B. (2008). Hazardous substances in waste electrical and electronic equipment. Rakesh Johri, ewaste: Implications, regulations and management in India and current global best practices, TERI, New Delhi.

[17] Asia E-waste Project. (2009). The E-waste Inventory Project in Malaysia. Available from: http://www.env.go.jp/en/recycle/asian_net/Project_N_Research/E-wasteProject/06.pdf [Accessed 18 November, 2013].

[18] Granzin, K. L., \& Olsen, J. E. (1991). Characterizing participants in activities protecting the environment: a focus on donating, recycling, and conservation behaviors. Journal of Public Policy \& Marketing, 1-27. 